\title{
Study of the Fracture Behavior of Mortar and Concretes with Crushed Rock or Pebble Aggregates
}

\author{
Sebastião Ribeiro*, Diego de Campos Ribeiro, Mateus Botani de Souza Dias, \\ Giseli Cristina Ribeiro Garcia, Ésoly Madeleine Bento dos Santos
}

\author{
Department of Materials Engineering - DEMAR, Lorena School of Engineering - EEL, \\ University of São Paulo - USP, Estrada Santa Lucrecia $s / n$, Bairro Mondezir, \\ CP 116, CEP 12600-970, Lorena, SP, Brazil
}

Received: September 8, 2010; Revised: December 23, 2010

\begin{abstract}
The objective of this work was to compare the fracture energy of mortar and concretes produced with crushed rock and pebble aggregates using zero, 10,20,30 and 40\% of aggregates mixed with standard mortar and applying the wedge splitting method to achieve stable crack propagation. The samples were cast in a special mold and cured for 28 days, after which they were subjected to crack propagation tests by the wedge splitting method to determine the fracture energies of the mortar and concrete. The concretes showed higher fracture energy than the mortar, and the concretes containing crushed rock showed higher resistance to crack propagation than all the compositions containing pebbles. The fracture energy varied from 38 to $55 \mathrm{~J}^{-2} \mathrm{~m}^{-2}$. A comparison of the number of aggregates that separated from the two concrete matrices with the highest fracture energies indicated that the concrete containing pebbles crumbled more easily and was therefore less resistant to crack propagation.
\end{abstract}

Keywords: portland cement, mortar, concrete, crushed rock, pebbles

\section{Introduction}

Concrete, the second most widely used material worldwide, can be defined as a macroscopically heterogeneous material whose properties depend on its phases, on their relationship to each other, and on its constituents ${ }^{1-8}$.

The materials commonly used for the production of concretes are Portland cement, sand, aggregates, additives and water. Each of these components has a specific function ${ }^{3,6,7,9}$.

Hardening of concretes take place in the curing stage, which is very important from the structural standpoint since this is the stage when the interactions among the initial and final constituents of the concrete are defined. Concrete curing time is variable, but at seven days of age, normal concretes usually reach $80 \%$ of the final strength they will have achieved after 28 days ${ }^{10}$.

Concretes are materials with complex structures composed of several starting materials, which are also complex, which makes them difficult to understand, e.g., the problem of interactions between matrix/aggregates, the region between the aggregate and the matrix, the size and quantity of aggregates, and so forth ${ }^{1,2,8,9}$. For example, the size and amount of aggregates have been shown to influence the fracture energy and fracture toughness of concretes ${ }^{8}$.

The matrix can be constituted of different materials in variable quantities which can modify their properties, e.g., the cement/water ratio, cement/sand ratio, among others. The same applies to the aggregate, which may consist of pebbles, which is basically $\mathrm{SiO}_{2}$, with smooth rounded surfaces, or of crushed rock with irregular shapes and with varied chemical and mineralogical compositions and highly rough surfaces. The shape and texture of aggregates have an important effect on the interlocking between mortar and aggregate ${ }^{9-14}$.

Depending on the properties of their raw materials, concretes may present a strong matrix and aggregate, a strong matrix and weak aggregate, or a weak matrix and strong aggregate. Lastly, in any of the aforementioned situations, there is the interfacial transition zone, ITZ - the region between the aggregate and the matrix, which is normally weaker where the probability of a crack surrounding an aggregate is high ${ }^{9,12,15,16}$.

Depending on the pathway of the crack, aggregates may display two basic behaviors: one, in which the aggregates are pulled out of the matrix, and the other, in which the aggregates become fractured. This behavior can be evaluated on the two fracture surfaces of a sample subjected to the stable crack propagation test ${ }^{12}$.

When the crack propagates in the ITZ, which is considered weak in relation to the matrix, and the aggregates are fairly strong, they are dislodged from the matrix rather than fractured, with little consumption of energy. This interfacial region may even display points where the aggregate/matrix interface is completely detached. The opposite may also occur, since the aggregates may be strongly bonded to the mortar, becoming fractured during the crack opening process $^{1,2,12}$.

To study the fracture behavior of the mortar and concretes, the wedge splitting method was used to produce stable crack propagation in the sample, which is a necessary situation for calculating fracture energy ${ }^{17-25}$. The wedge splitting method was patented in 1986 by Tschegg ${ }^{26}$ and since then numerous studies have focused on improving this test, which is currently performed with well designed and accurate devices, as well as highly accurate testing machines. This favors the stable propagation of the crack, a thermodynamic condition of transformation of elastic energy stored in the testing machine and the sample into surface energy per unit of newly formed crack surface ${ }^{5,27-32}$. Fracture energy, which represents the energy per unit of the fracture area of mortars and concretes, can be calculated by the following equation ${ }^{5,19,21,23,24,27,31-33}$ : 


$$
\gamma_{w o f}=\frac{1}{2 A} \int P d s
$$

where $A$ is the projected area of the fracture surface, $P$ is the vertical load applied by the testing machine, and $s$ is the displacement of the machine's actuator. The value of the integral $P d s$, which is determined by integrating the area under the load-displacement curve, indicates the total work of fracture.

The fracture energy results reported in the literature vary significantly because the authors of these studies used different compositions, raw materials, preparation conditions and methodologies

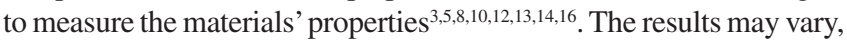
for example, from 10 to $200 \mathrm{~J} . \mathrm{m}^{-2}$.

\section{Materials and Methods}

\subsection{Materials}

The materials used here were crushed rock with a maximum size of $9.5 \mathrm{~mm}$ and minimum size of $4.75 \mathrm{~mm}$, pebbles in the same granulometric range, washed medium-grained sand with a mean size of $500 \mu \mathrm{m}$, maximum size not exceeding $2800 \mu \mathrm{m}$ and minimum $53 \mu \mathrm{m}$, Portland CPII-E-32 cement manufactured according to the Brazilian NBR 11578/1991 standard, and potable water. These aggregates have different shapes and surfaces. Crushed rock is irregular with rough surfaces while pebbles are rounded and have smooth surfaces. Crushed rock aggregate consists of a mineral complex whose main minerals are quartz, feldspars, cordierite and anortite. Pebbles are composed only of $\mathrm{SiO}_{2}$ in the form of quartz mineral. The mineral compositions of these aggregates were determined by X-ray diffraction, applying $2 \theta$ from 10 to $90^{\circ}$.

\subsection{Molding of mortar and concrete samples}

Initially, a mortar was produced with a composition of 1:2 in weight of cement:sand and water, with a quantity of water of 0.46 relative to the weight of cement. This composition was chosen (1:2 rather than 1:3) to work with a mortar more resistant to crack propagation. The mortar was cast in a special mold to produce notch and grooves on the samples. The samples were demolded 24 hours after casting.

The above described mortar was used for the production of the concrete samples by adding crushed rock or pebbles as aggregates, in proportions of 10, 20, 30 and 40\% in weight. Before the aggregates were added to the mortar, they were wetted and drained to prevent them from consuming water or contributing water to the mortar. For each material (mortar, concrete with crushed rock and concrete with pebbles), six samples with dimensions of $100 \times 100 \times 75 \mathrm{~mm}$ were used to measure the fracture energy, see Figure 1.

\subsection{Curing of the samples}

All the samples (mortars and concretes) were cured for 28 days at $25^{\circ} \mathrm{C}$ in a chamber with a moisture-saturated atmosphere. After two days of curing, the samples were subjected to stable crack propagation tests to study the fracture of the three materials: mortar, concrete with crushed rock, and concrete with pebbles.

Figure 1 shows a mortar specimen representative of all the samples used in this work, ready to be subjected to the stable crack propagation test by the wedge splitting method.

\subsection{Crack propagation tests by the wedge splitting method}

The mortar and concrete samples were subjected to stable crack propagation tests using an MTS model $810 \mathrm{M}$ universal testing machine operating at an actuator speed of $30 \mu \mathrm{m} / \mathrm{min}$. Load vs.

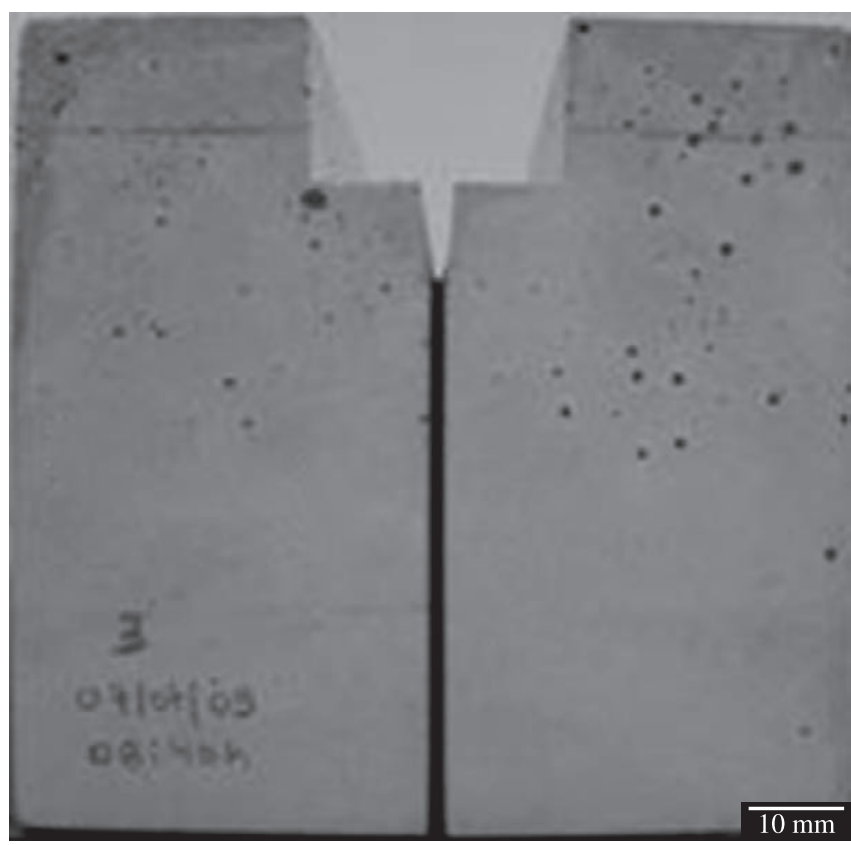

Figure 1. Photograph of the mortar sample prior to the stable crack propagation test by the wedge splitting method.

displacement curves were built based on the load and displacement data of the load cell. Loads were measured using a $5 \mathrm{kN}$ load cell with $5 \mathrm{~N}$ resolution, model MTS 661-19F-01. The software programs used to control the test were TestStar-790.00, version 4.0E and TestWare-SX, version 4.0D. The MTS actuator was operated with a displacement of $0.03 \mathrm{~mm} / \mathrm{min}$. The work of fracture was then determined based on these curves, using Origin Pro 7.5 software, while the fracture energies were calculated from the projected fracture area of the specimens, using Equation 1. Total, dislodged, fractured and mixed aggregates were counted on the surfaces of the specimens using a stereoscopic microscope.

\subsection{Structures of the samples}

The structures of the three materials were examined using a LEIKA DM IRM optical microscope equipped with LEIKA QWIN Stander imaging software, a LEO model 1450 VP scanning electron microscope, and conventional photographs of polished surfaces and fracture surfaces. In addition to the microstructural analyses, chemical analyses were carried out by energy dispersive spectrometry (EDS). The behavior of the aggregate and matrix (detached, fractured and mixed) was evaluated using a QUIMIS model Q740Z-TR stereoscopic microscope coupled to a KODO KC-512DN Color Camera.

\section{Results and Discussion}

Figure 2 shows the general structure of two concrete samples, one with pebbles and the other with crushed rock (a and b). These micrographs show coarse pebble aggregates (a) and crushed rock aggregate (b), and fine sand grains, as well as the cement matrix with finer particles. Both cases reveal a heterogeneous and complex microstructure in which the coarse aggregates are embedded in the mortar matrix.

Figures 3 and 4 depict samples after the stable crack propagation test by the wedge splitting method. The fractured parts of the sample represent the behavior of the matrix and the aggregates when the crack runs through the entire section, indicating when the aggregate is completely detached from one of the sides, and showing the respective 


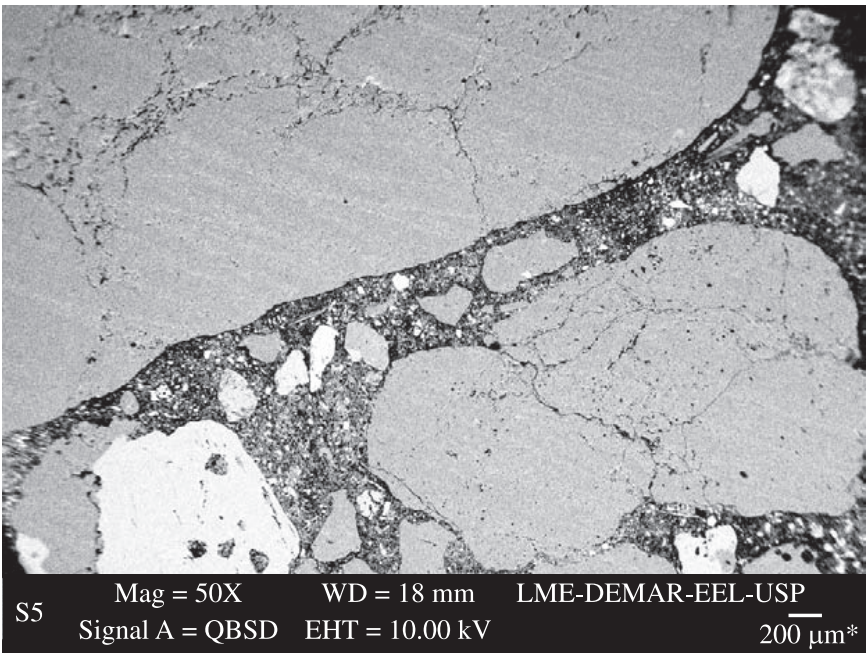

(a)

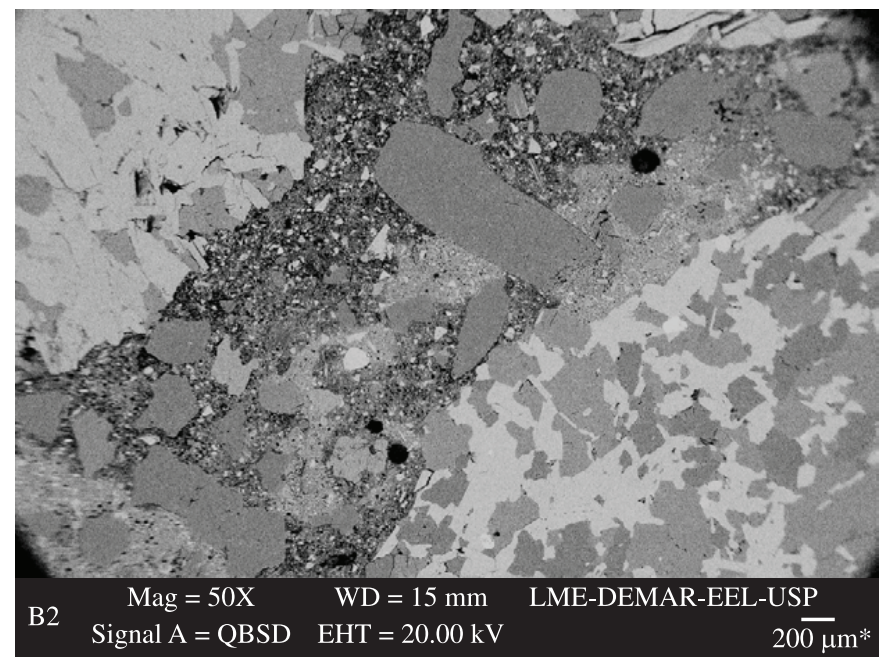

(b)

Figure 2. Backscatter SEM micrograph of a concrete containing: a) pebbles; and b) crushed rock.

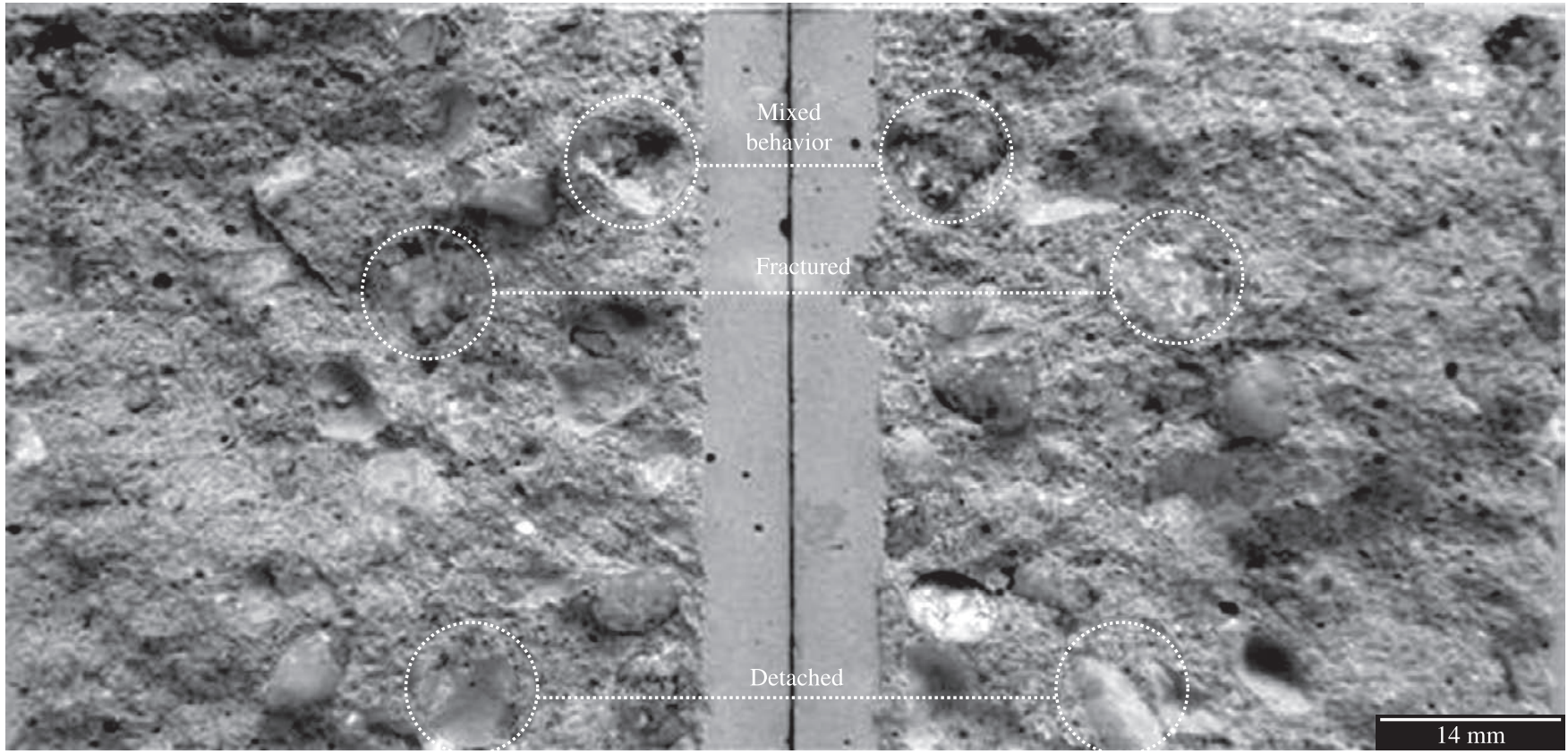

Figure 3. Photograph of a sample of concrete containing pebble aggregate after the fracture test by the wedge splitting method.

hole on the other side. Also clearly visible are the two parts of the fractured aggregate, with its respective fractions held in the matrix. This mixed behavior occurs when part of the aggregate is partially fractured and part of it is detached from one side, remaining trapped at the other side.

Table 1 illustrates the behavior of the pebble and crushed rock aggregates in the concretes under study. At least five fractured samples of each composition were used to count the aggregates, based on the fractured surfaces illustrated in Figures 3 and 4. The detached, fractured and mixed aggregates were counted using a stereoscopic microscope.

An evaluation of the results listed in Table 1 indicates that, in all the compositions, the number of aggregates detached from the concrete containing pebbles is much larger than from the one containing crushed rock, and that the opposite applies to the fractured
Table 1. Behavior of the aggregates in concrete containing crushed rock aggregate and in concrete containing pebble aggregates.

\begin{tabular}{|c|c|c|c|c|}
\hline \multirow{2}{*}{\multicolumn{2}{|c|}{$\begin{array}{c}\text { Concrete } \\
\text { (identification) }\end{array}$}} & \multicolumn{3}{|c|}{ Behavior of the aggregates } \\
\hline & & Fractured (\%) & Detached $(\%)$ & Mixed (\%) \\
\hline \multirow{4}{*}{$\begin{array}{l}\text { Crushed } \\
\text { rock }\end{array}$} & 10 & 60.92 & 23.12 & 15.96 \\
\hline & 20 & 63.19 & 22.49 & 14.41 \\
\hline & 30 & 55.78 & 27.64 & 16.58 \\
\hline & 40 & 63.48 & 27.42 & 9.10 \\
\hline \multirow{4}{*}{ Pebble } & 10 & 21.35 & 56.17 & 22.48 \\
\hline & 20 & 20.67 & 54.47 & 24.86 \\
\hline & 30 & 21.52 & 55.63 & 23.18 \\
\hline & 40 & 26.47 & 57.94 & 15.59 \\
\hline
\end{tabular}


aggregates, where the concrete with crushed rock shows higher values. The reason for this behavior is quite obvious when one evaluates the aggregate-matrix interactions, especially considering roughness. This property provides good anchorage, favoring a better interaction between the crushed rock and the matrix when compared with the pebble-matrix interaction, as can be seen by comparing the interfacial regions in Figure $2 \mathrm{a}$ and $\mathrm{b}$. The path of the principal crack deflects from the surface of the pebble, thus requiring less energy to propagate than cracks in crushed rock. Therefore, this justifies the higher resistance to crack propagation in the concretes with crushed rock than in those with pebbles, as will be discussed below.

Figure 5 illustrates the behavior of the pebble aggregate when it is dislodged from the matrix, showing a smooth surface in (a). In (b), note the hole left by the dislodged pebble. This is a clear indication that the aggregate/matrix interface was weaker than the aggregate, allowing the aggregate to become dislodged rather than fractured.
Figure 6 shows the crushed rock aggregate detached from the matrix (a), and the region from which the respective aggregate was detached, called the "hole" (b). In this figure, note that the detached aggregate does not have a smooth surface like that of a pebble and that it appears encrusted by the material of the matrix, Figure $6 \mathrm{a}$, indicating that the interaction between aggregate and matrix is stronger in concretes with crushed rock than in concretes with pebbles. Note, also, that the surface of the hole from which the aggregate was detached is not as smooth as the one shown in Figure 5b, which represents a hole produced by a dislodged pebble in the concrete containing pebble aggregate.

Figure 7 shows three representative load-displacement curves chosen randomly among the tested samples: a) mortar 1:2; b) concrete with pebbles; and c) concrete with crushed rock.

The curves show stable crack propagation behavior, indicating that elastic deformation occurs as the load increases until the

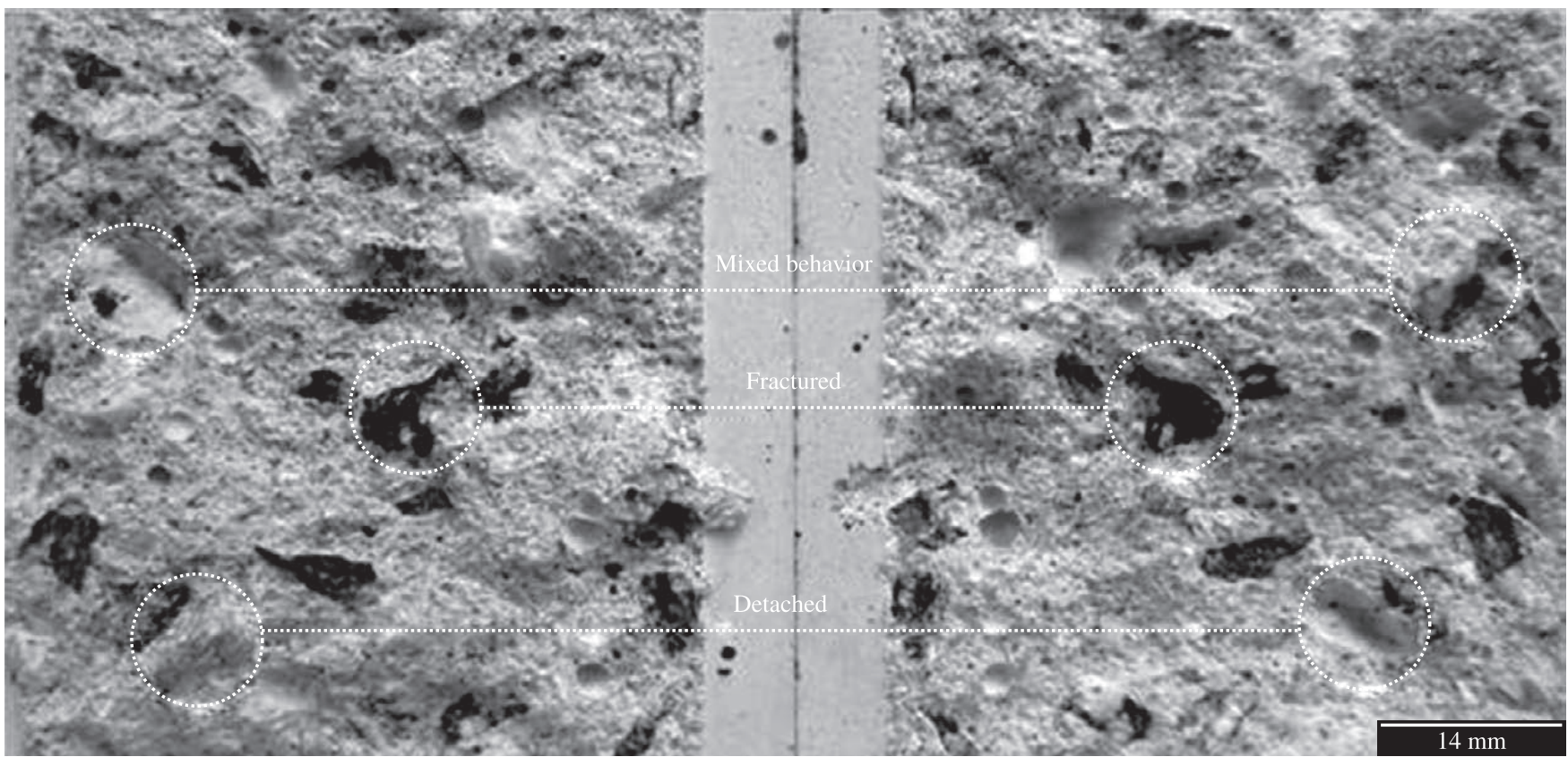

Figure 4. Photograph of a sample of concrete containing crushed rock aggregate after the fracture test by the wedge splitting method.

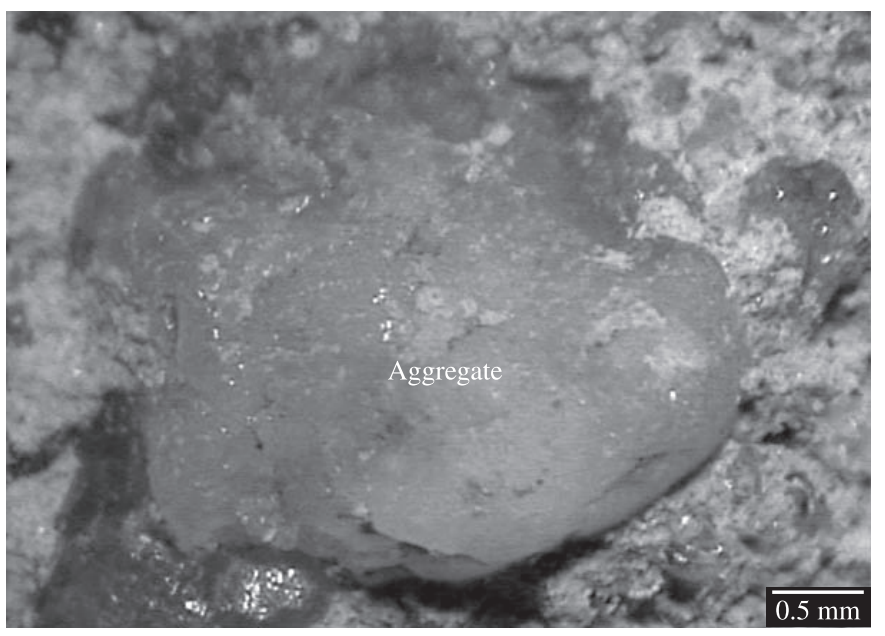

(a)

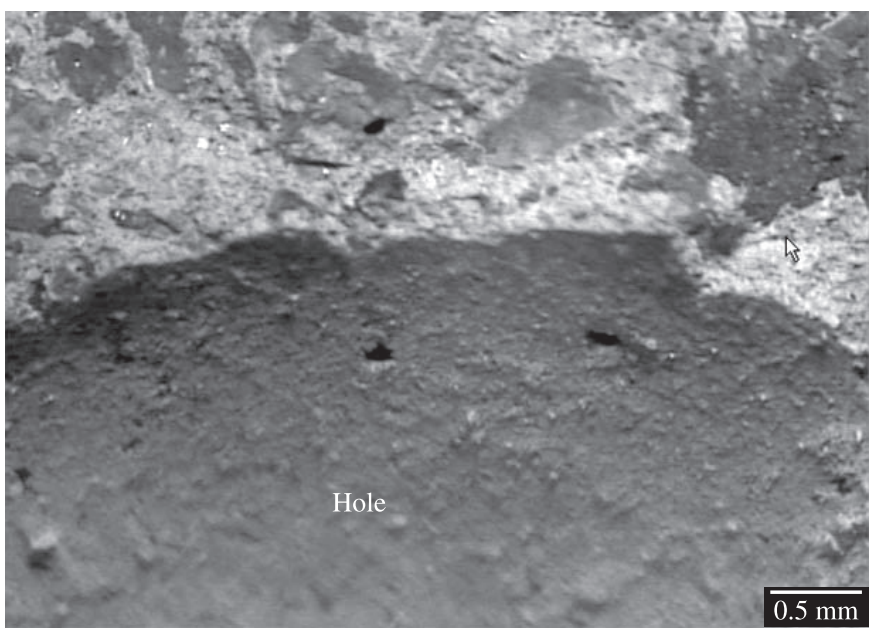

(b)

Figure 5. Optical microscopy images of the fracture surface of the concrete with pebbles: a) detail of the aggregate dislodged from the matrix; and b) hole left behind by the dislodged aggregate. 


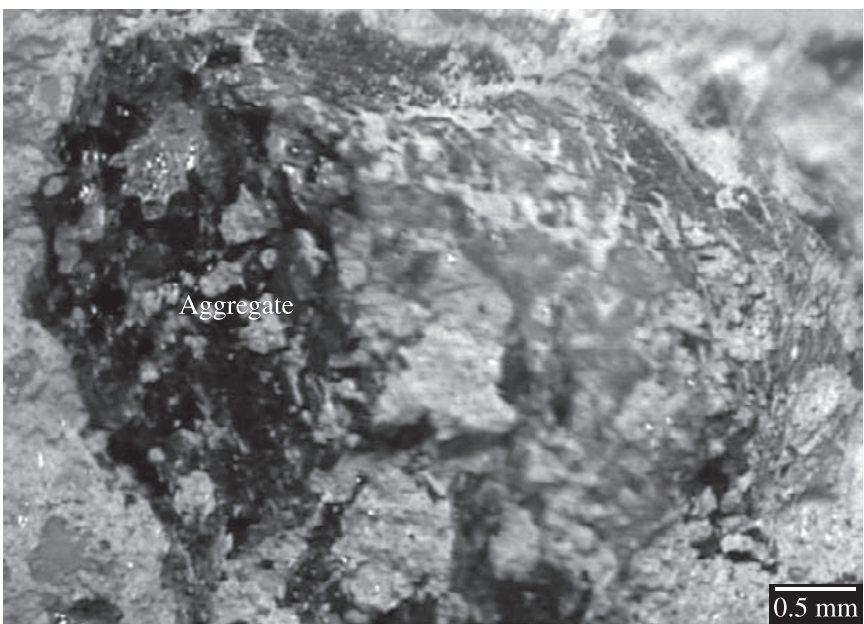

(a)

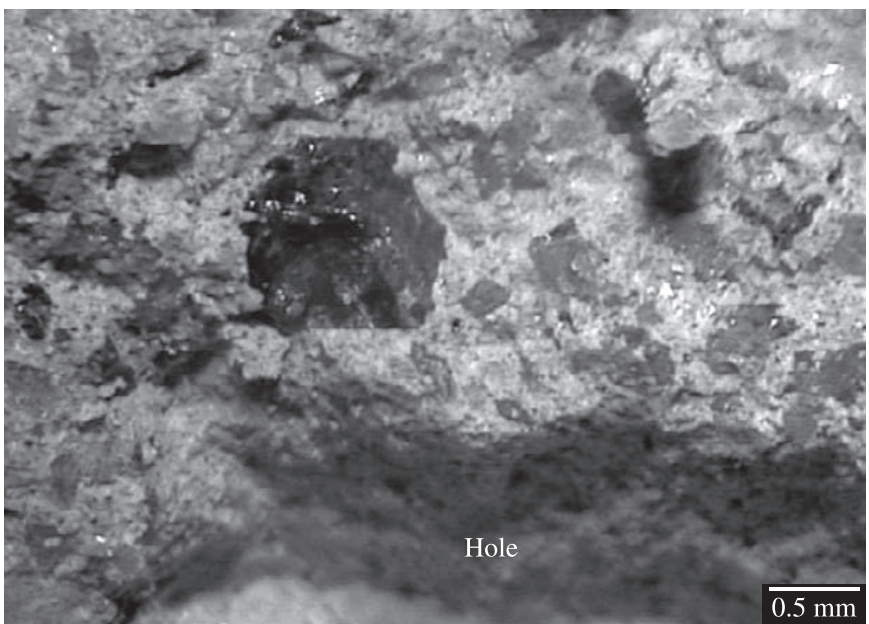

(b)

Figure 6. Optical microscopy images of the fracture surface of the concrete with crushed rock: a) detail of the aggregate detached from the matrix; and b) hole left behind by the detached aggregate.

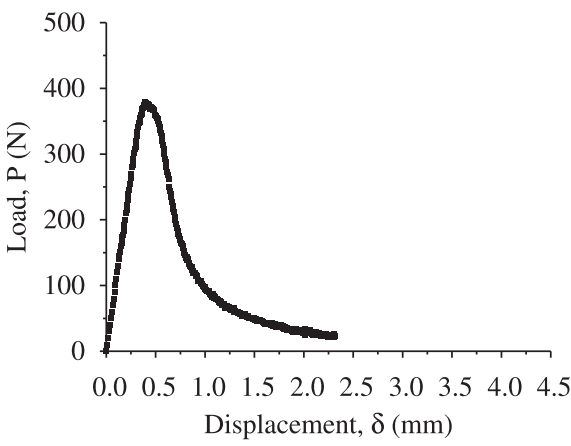

(a)

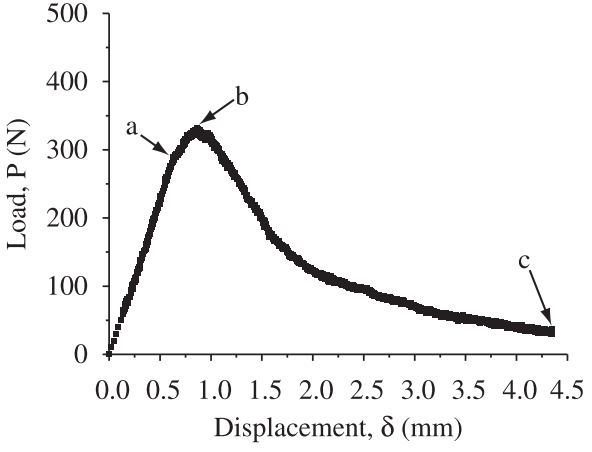

(b)

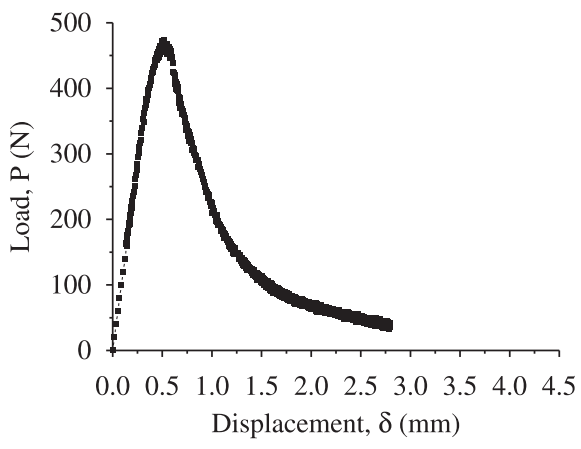

(c)

Figure 7. Representative load-displacement curves of the samples of a) mortar; b) concrete with pebbles; and c) concrete with crushed rock.

maximum load is reached, whereupon this deformation begins to diminish, indicating a damping behavior. Also note the three distinct regions in these curves, one of them indicating the elastic deformation of the samples (region 0 -a), another characterized by the onset and growth of the crack (region a-b), and lastly the region of crack propagation (region b-c), characterized by damping of the curve. The behavior and characteristics of these curves depend on each material, and provide inputs for a perfect evaluation of the fracture behavior of concretes and mortars. It is important to note the differences between the two concretes. The maximum load of the concrete with pebbles is lower than that of the concrete with crushed rock. However, the two concretes show opposite displacement behavior, indicating that the concrete containing crushed rock is stiffer than that containing pebble, but less resistant to crack propagation. This behavior is illustrated in Figure $7 \mathrm{~b}$ and $\mathrm{c}$, which shows a displacement of approximately $4.5 \mathrm{~mm}$ for concrete with pebbles and of $2.8 \mathrm{~mm}$ for concrete with crushed rock.

Figure 8 shows the fracture energy of the three materials of this study. The mortar was used for purposes of comparison, since it was employed to produce the concretes with added aggregates.

Upon examining Figure 8 one can see that the fracture energy of the mortar is lower than that of the concretes. The addition of

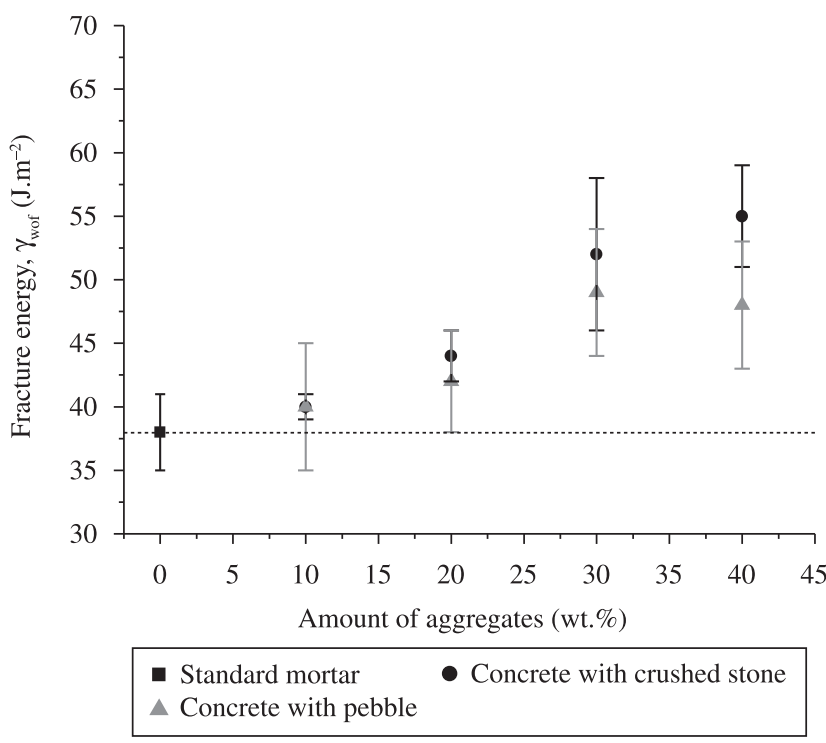

Figure 8. Fracture energy of the 1:2 mortar and of the concretes containing $10,20,30$ and 40 wt. (\%) of pebbles or crushed rock. 
aggregates increases the fracture energy, causing the concretes to present a certain degree of reinforcement due to the binding effect of the aggregates in the matrix.

In both concretes, the fracture energy increased in proportion to the quantity of aggregates added to them. These results are consistent with other findings reported in the literature, which indicate that the fracture energy increases with the quantity of aggregate ${ }^{8,14}$.

A comparison of the values of fracture energy for the two types of aggregate reveals that concrete containing crushed rock showed higher fracture energy. This finding is consistent with the literature ${ }^{8,14}$. The higher fracture energies of concretes with crushed rock can be attributed to the greater interaction between the rough aggregates and the matrix, which did not allow for the formation of regions of weaker binding with the mortar. Other mechanisms that spend energy may also occur during the fracture of the crushed rock aggregate. However, this did not occur with the concrete containing pebbles, in which the aggregate-matrix interaction differed considerably because the smoother surface of the aggregates did not provide effective anchoring. This produces a zone of low adherence and hence lower resistance to crack propagation, translating into lower fracture energies. These statements are supported by the results shown in Figures 3 and 4, in Table 1, and in the literature ${ }^{8,12,13,14}$.

\section{Conclusions}

Concretes with crushed rock as aggregate are more resistant to crack initiation but less resistant to crack propagation than concrete produced with pebbles as aggregate, considering aggregates in same size range. Less energy is consumed in elastic deformation than in crack propagation in concrete. This behavior is more enhanced in concrete containing pebble aggregates.

Due to their irregular and rougher surface and other possible mechanisms that consume the energy of crushed rock aggregate, concretes containing crushed rock have higher fracture energy than those containing pebble aggregates.

Due to their smoother surface and therefore weaker anchorage, pebble aggregates present areas dislodged from the matrix, leading to lower values of fracture energy, since the crack follows these regions without consuming energy.

The physical structure of aggregates is also important, since crushed rock aggregates show internal cracks due to the compressive forces applied during the crushing process, while pebbles are bodies that shift back and forth by the action of water, causing them to collide with one another and form cracks. This characteristic of aggregates can influence the properties of concrete.

Although the concretes containing pebbles exhibited lower values of fracture energy in the compositions studied here than in those containing crushed rock, they are applicable in civil construction. The important point is to know the resistance values of concretes with pebble aggregates in order to employ them in specific cases.

\section{Acknowledgements}

The authors gratefully acknowledge the financial support of this work by FAPESP (Fundação de Amparo à Pesquisa do Estado de São Paulo) through process 2007/55964-3, and by CNPq (Conselho Nacional de Desenvolvimento Científico e Tecnológico) through a Research Productivity Grant, process 302387/2007-2.

\section{References}

1. Stroeven P. A stereological approach to roughness of fracture surfaces and tortuosity of transport paths in concrete. Cement and Concrete Composite. $2000 ; 22: 331-341$.
2. Sadowski T and Golewski G. Effect of aggregate kind and graining on modeling of plain concrete under compression. Computational Materials Science. 2008; 43:119-126.

3. Xiao J, Schneider H, Dönnecke C and König G. Wedge splitting test on fracture behaviour of ultra high strength concrete. Construction and Building Materials. 2004; 18:359-365.

4. Rosselló $\mathrm{C}$ and Elices M. Fracture of model concrete: 1. Types of fracture and crack path. Cement and Concrete Research. 2004; 34:1441-1450.

5. Ribeiro S, Santos EMB, Garcia GCR and Rodrigues JA. Elastic work and fracture energy of concretes made with crushed stones and pebbles aggregates. Materials Science Forum. 2010; 636-637:1215-1221.

6. Wu KR, Chen B, Yao W and Zhang D. Effect of coarse aggregate type on mechanical properties of high-performance concrete. Cement and Concrete Research. 2001; 31:1421-1425.

7. Guinea GV, El-Sayed K, Rocco, CG, Elices M and Planas J. The effect of the bond between the matrix and the aggregates on the cracking mechanism and fracture parameters of concrete. Cement and Concrete Research. 2002. 12:1961-1970.

8. Chen B and Liu J. Effect of aggregate on the fracture behaviour of high strength concrete. Construction and Building Materials. 2004; 18:585590.

9. Prokopski G and Halbiniak J. Interfacial transition zone in cementitious materials. Cement and Concrete Research. 2000; 30:579-583.

10. Nilica R and Harmuth H. Mechanical and fracture mechanical characterization of building materials used for external thermal insulation composite systems. Cement and Concrete Research. 2005; 35:1641-1645.

11. Donza $\mathrm{H}, \mathrm{Cabrera} \mathrm{O}$ and Irassar EF. High-strength concrete with different fine aggregate. Cement and Concrete Research. 2002; 32:1755-1761.

12. Eleces M and Rocco CG. Effect of aggregate size on the fracture and mechanical properties. Engineering Fracture Mechanics. 2008; 75:38393851.

13. Rocco CG and Elices M. Effect of aggregate shape on the mechanical properties of a simple concrete. Engineering Fracture Mechanics. 2009; 76:286-298.

14. Amparano FE, Xi, Y and Roh, Y-S. Experimental study on the effect of aggregate content on fracture behavior of concrete. Engineering Fracture Mechanics. 2000; 67:65-84.

15. Lothenbach B, Le Saout G, Gallucci E and Scrivener K. Influence of limestone on the hydration of Portland cements. Cement and Concrete Research. 2008; 38:848-860.

16. Yan A, Wu K-R, Zhang D and Yao W. Effect of fracture path on the fracture energy of high-strength concrete. Cement and Concrete Research. 2001; 31:1601-1606.

17. Barinov SM. The work-of-fracture of brittle materials: Principle, determination, and applications. Journal Material Research; 1994; 6(9):1412-1424.

18. Hillerborg A, Modéer M and Peterson P-E. Analysis of crack formation and crack growth in concrete by means of fracture mechanics and finite elements. Cement and Concrete Research. 1976; 6:773-781.

19. Harmuth H. Stability of crack propagation associated with fracture energy determined by wedge splitting specimen. Theoretical and Applied Fracture Mechanics. 1995; 23:103-108.

20. Sakay M and Bradt RC. Graphical methods for determining the nonlinear fracture parameter of silica and graphite refractory composites. In: Fracture mechanical of ceramics. New York: Publishing Corporation; 1986. p. 127-142.

21. Sakai M and Bradt RC. Fracture toughness testing of brittle materials. International Materials Reviews. 1993; 2(38):53-78.

22. Nakayama J. A bending method for direct measurement of fracture energy of brittle material. Journal Applied Physics. 1964; 3:422-423.

23. Nakayama J. Direct measurement of fracture energies of brittle heterogeneous materials. Journal of the American Ceramic Society. 1965; 18(11):583-587. 
24. Nakayama J, Abe H and Bradt RC. Crack stability in the work-of-fracture test: Refractory application. Journal of the American Ceramic Society. 1981; 64(11):671-675.

25. Harmuth H, Rieder K, Krobath M and Tschegg E. Investigation of the nonlinear fracture behaviour of ordinary ceramic refractory materials. Materials Science \& Engineering A. 1996; 214:53-61.

26. Tschegg E. Republik Österreich. Patent number 390328B; 1986.

27. Harmuth $\mathrm{H}$ and Tschegg EK. Fracture mechanical characteristic of ordinary ceramic refractory materials. Veitsch-Radex Rundschau. 1994; 2(1):465-479

28. Trunk B, Schober G, Helbling AK and Wittmann FH. Fracture mechanics parameters of autoclaved aerated concrete. Cement and Concrete Research. 1999; 29:855-859.
29. Tschegg EK, Fendt KT, Manhart C and Harmuth H. Uniaxial and biaxial behaviour of refractory materials. Engineering Fracture Mechanics. 2009; 76:2249-2259.

30. Auer T, Manhart $\mathrm{C}$ and Harmuth $\mathrm{H}$. Contributions to refractory fracture mechanical and fractographic investigations. RHI Bulletin. 2006; 1:38-41.

31. Larson DR, Coppola JA and Hasselman DPH. Fracture toughness and spalling behavior of high- $\mathrm{Al}_{2} \mathrm{O}_{3}$ refractories. Journal of the American Ceramic Society. 1974; 57(10):417-421.

32. Ribeiro S and Rodrigues JA. The influence of microstructure on the maximum load and fracture energy of refractory castables. Ceramics International. 2010; 36:263-274.

33. Chou C-C, Cheng I-L, Chen K-J and Ko Y-C. Fracture energy and thermal stress resistance parameter of high alumina brick. Ceramic Bulletin. 1986; 65(7):1042-1046 